\title{
Propriedades Psicométricas da Escala Multidimensional de Expressão Social - Parte Motora (EMES-M) em uma Amostra Brasileira
}

\author{
Anderson Siqueira Pereira ${ }^{1}$ \\ Universidade Federal do Rio Grande do Sul, Porto Alegre-RS, Brasil \\ Luciana Dutra-Thomé \\ Universidade Federal da Bahia, Salvador-BA, Brasil \\ Silvia Helena Koller \\ Universidade Federal do Rio Grande do Sul, Porto Alegre-RS, Brasil
}

\section{RESUMO}

O presente artigo tem por objetivo descrever o processo de adaptação e validação da Escala Multidimensional de Expressão Social parte Motora (EMES-M) para o contexto brasileiro. A expressão social motora consiste nas habilidades sociais, que são preditores de qualidade de vida e da qualidade das relações interpessoais. A amostra foi composta de 925 indivíduos de ambos os sexos, entre 18 e 35 anos. Foram realizadas análises fatoriais confirmatórias com um modelo de oito fatores teoricamente baseados. A escala apresentou propriedades psicométricas adequadas, com CFI 0,910, TLI de 0,904, RMSEA de 0,049 e consistência interna da escala total de 0,945 . Também apresentou validade convergente, medida a partir de correlações com escalas que avaliam assertividade e ansiedade social. A partir dos resultados, conclui-se que a escala pode ser utilizada em contextos de pesquisa para avaliar as habilidades sociais.

Palavras-chave: habilidades sociais, psicometria, escala de avaliação.

\begin{abstract}
Psychometric Properties of the Multidimensional Social Expression Scale - Motor (EMES-M) in a Brazilian Sample

The present article aims to describe the process of adaptation and validation of the Multidimensional Social Expression Scale Motor Part (EMES-M) for the Brazilian context. Motor social expression consists of social skills, which are predictors of quality of life and interpersonal relationship quality. The sample consisted of 925 individuals of both sexes, between 18 and 35 years old. Confirmatory factor analyses were performed with a theoretically based eight-factor model. The scale had adequate psychometric properties, with CFI 0.910, TLI of 0.904, RMSEA of 0.049 and internal consistency of the total scale of 0.945 . It also presented convergent validity, measured from correlations with scales that evaluate assertiveness and social anxiety. From the results, we conclude that the scale can be used in research contexts to evaluate social skills.7
\end{abstract}

Keywords: social skills, psychometry, evaluation scale.

\section{RESUMEN - Propiedades Psicométricas de la Escala Multidimensional de Expresión Social -Parte Motora (EMES-M) en una Muestra Brasileña}

Este artículo tiene como objetivo describir el proceso de adaptación y validación de la Escala Multidimensional de Expresión Social Parte Motora (EMES-M) en el contexto brasileño. La expresión social motora consiste en habilidades sociales que son predictores de la calidad de vida y la calidad de las relaciones interpersonales. La muestra fue compuesta por 925 individuos de ambos sexos, entre 18 y 35 años. Se realizaron análisis factoriales confirmatorios con un modelo de ocho factores fundamentados teóricamente. La escala mostró propiedades psicométricas adecuadas con CFI 0,910, TLI de 0,904, RMSEA de 0,049 y consistencia interna de la escala total de 0,945. También presentó validez convergente, medida a partir de correlaciones con escalas que evalúan asertividad y ansiedad social. De acuerdo a los resultados se puede decir que la escala es adecuada para ser utilizada en contextos de investigación para evaluar las habilidades sociales.

Palabras clave: habilidades sociales, psicometría, escala de evaluación.

O objetivo deste artigo é relatar o processo de adaptação da Escala Multidimensional de Expressão Social - Parte Motora para o contexto brasileiro e apresentar suas propriedades psicométricas. A expressão social motora ou habilidades sociais podem ser definidas como comportamentos por meio dos quais são expressas ideias, opiniões e sentimentos, auxiliando as pessoas a lidarem com situações sociais, se comunicar,

${ }^{1}$ Endereço para correspondência: Avenida Taquari, 635, apto 102, Cristal, 90810-180, Porto Alegre-RS. Tel.: (51) 98567-0551. E-mail: anderson.siqueira.pereira@gmail.com Agradecimentos: Esta pesquisa foi realizada com auxílio de bolsa de pesquisa fornecida pelo Conselho Nacional de Desenvolvimento Científico e Tecnológico (CNPq) 
resolver e prevenir problemas nas relações interpessoais (Caballo, 2003). Neste artigo, as expressões sociais motoras serão apresentadas como habilidades sociais, pelo fato de esse termo ser predominantemente utilizado na literatura psicológica. Como exemplos de habilidades sociais, pode-se citar: iniciar e manter conversações, empatia, saber dizer não, expressar desagrado, contato visual, postura, saber ouvir e a hora de falar em uma conversação, expressar afetos positivos e negativos de forma assertiva, fazer perguntas, fazer e aceitar críticas e elogios, entonação de voz, gestos, entre outros.

O repertório de habilidades sociais desenvolve-se durante toda a vida. Déficits nesse repertório podem acarretar em dificuldades nas interações sociais cotidianas para lidar com problemas sociais, o que pode resultar em posturas agressivas ou passivas frente aos demais, ou até mesmo a transtornos sociais (ex.: fobia social; Wagner, Pereira, \& Oliveira, 2014). Além disso, diversos estudos apontam associação entre déficits de habilidades sociais e transtornos psicológicos, como depressão (Del Prette \& Del Prette, 2002; Segrin, 2000), transtornos de ansiedade (Bandeira, Quaglia, Bachetti, Ferreira \& Souza 2005; Del Prette \& Del Prette, 2009), tentativas de suicídio (Pereira, Willhem, Koller, \& Almeida, no prelo) e esquizofrenia (Penn, Kohlmaier, \& Corrigan, 2000). Por outro lado, um repertório adequado de habilidades sociais auxilia no desempenho social satisfatório, na autoestima, na autoeficácia e na qualidade de vida (Bandeira et al., 2005; Carneiro \& Falcone, 2004; Pereira, Dutra-Thomé, \& Koller, 2016).

Para entender e avaliar a expressão social dos indivíduos, deve-se levar em conta tanto os aspectos comportamentais (ou motores) quanto os pensamentos (ou cognitivos) envolvidos na interação social. No intuito de desenvolver uma avaliação multidimensional das habilidades sociais, foram desenvolvidas as Escalas Multidimensionais de Expressão Social (Caballo, 1993; Caballo \& Ortega, 1989). Elas são compostas por duas escalas: a Escala Multidimensional de Expressão Social parte Motora (EMES-M) e a Escala Multidimensional de Expressão Social parte Cognitiva (EMES-C), que buscam avaliar como se dá a expressão de ambos aspectos que influenciam o desempenho social dos indivíduos. A EMES-M é uma escala que tem por objetivo avaliar a frequência de comportamentos socialmente hábeis nos contextos em que as pessoas estão inseridas. Por sua vez, a EMES-C foi desenvolvida com o intuito de avaliar a ocorrência de pensamentos negativos relacionados à interação social. Ambas as escalas podem ser utilizadas em meio clínico, no qual os profissionais podem identificar em quais áreas os pacientes apresentam maiores déficits nas habilidades sociais. Com esse dado, é possível elaborar intervenções que possam suprir esses déficits, bem como identificar situações nas quais cognições negativas atrapalham a execução de comportamentos socialmente hábeis. Elas também podem ser utilizadas no contexto de pesquisa, fornecendo dados sobre déficits e padrões de habilidades sociais em populações diversas (Caballo, 2003). No presente artigo, o foco será na descrição específica do processo de adaptação e na avaliação das propriedades psicométricas da EMES-M para o contexto brasileiro. Não será descrito o processo da escala EMES-C (em fase de desenvolvimento). Dados preliminares podem ser encontrados no trabalho de Pereira (2015).

Em sua validação original para a população espanhola, a EMES-M é composta por sessenta e quatro itens, os quais trazem diversas situações sociais e comportamentos. Os respondentes devem marcar em uma escala de 0 (nunca ou muito raramente) a 4 (sempre ou com muita frequência) o quão frequentemente agem da forma como está descrito em cada item. Desses itens, 38 possuem valências negativas que devem ter suas pontuações invertidas para serem analisados. São eles os itens: $01,02,03,04,05,10,11,13,14,15,16,18,19$, $20,22,23,26,31,36,37,38,40,42,43,44,45,46,47$, $51,52,53,54,55,56,59,60,61$ e 63 . A análise fatorial do instrumento realizada por Caballo (1993) identificou 12 fatores, porém, dos 64 itens, 13 não foram incluídos dentro dessa estrutura fatorial $(02,06,08,10$, $11,16,22,28,29,35,42,51$ e 55), sem haver explicação do porquê na publicação original (Caballo, 1993). A consistência interna desse modelo foi de 0,92 . Os fatores e seus respectivos itens podem ser observados na Tabela 1.

Apesar da escala possuir tradução para o português brasileiro, a qual está disponível no livro "Manual de Avaliação e Treinamento em Habilidades Sociais" (Caballo, 2003), percebe-se a utilização de termos que estão atualmente em desuso, além de frases com problemas de concordância ou tradução. Outro ponto que chama a atenção é o uso de termos heteronormativos como "sexo oposto" para se referir a possíveis parceiros afetivos e sexuais. Além disso, nenhum estudo avaliando as propriedades psicométricas da versão em português foi realizado. Dessa forma, não existem dados que comprovem se a estrutura fatorial espanhola é válida para a realidade brasileira. Mesmo assim, as escalas foram utilizadas por alguns estudos para avaliar as habilidades sociais em amostras brasileiras (Landim et al., 2000; Sbicigo \& Lisbôa, 2009; Sztamfater \& Savóia, 2010). A fim de oferecer a profissionais e pesquisadores um instrumento adequado à realidade brasileira, o objetivo deste estudo é (a) realizar uma nova adaptação do instrumento para o português brasileiro, atualizando termos em desuso e avaliar as propriedades psicométricas dessa escala, avaliando sua estrutura fatorial; (b) avaliar a validade convergente do instrumento, utilizando construtos que são apontados pela literatura como relacionados às habilidades sociais, nomeadamente: ansiedade social (Angélico, Crippa, \& Loureiro, 2012; Wagner et al., 2014) e assertividade (Del Prette \& Del Prette, 2002, 2009). 
Tabela 1

Fatores e Itens da Validação Espanhola da EMES-M

\begin{tabular}{ll}
\hline \multicolumn{1}{c}{ Fatores } & \multicolumn{1}{c}{ Itens } \\
\hline 1. Iniciação de interações & $04,23,31,36,40,43,47,54,60$ e 63 \\
2. Falar em público/enfrentar superiores & $07,18,20,27,37,38,41,53,56$ e 63 \\
3. Defesa dos direitos de consumidor & $12,30,44$ e 58 \\
4. Expressão de incômodo, desagrado, aborrecimento & $14,15,24,34$ e 64 \\
5. Expressão de sentimentos positivos pelo sexo oposto & $45,48,54,59$ e 61 \\
6. Expressão de incômodo e aborrecimento por familiares & $33,39,49$ e 57 \\
7. Rejeição de pedidos provenientes do sexo oposto & 05,13 e 19 \\
8. Aceitação de gentilezas & $01,03,50$ e 52 \\
9. Tomar a iniciativa nas relações com o sexo oposto & 17,32 e 62 \\
10. Fazer gentilezas & 09,21 e 26 \\
11. Preocupação com os sentimentos dos outros & 26 e 46 \\
12. Expressão de carinho pelos pais & 25 \\
\hline
\end{tabular}

\section{Adaptação das Escalas para o Português Brasileiro}

Para realização deste estudo, inicialmente contatou-se o autor da escala original para pedido de autorização para a realização de uma nova tradução e validação para a população brasileira. Para o processo de adaptação do instrumento para o português brasileiro, foram utilizados os seguintes passos (Borsa, Damásio, \& Bandeira, 2012): 1. tradução: a escala foi traduzida por dois tradutores independentes, que possuem o português como língua nativa e fluência em espanhol; 2. síntese das traduções: um terceiro pesquisador realizou a síntese das duas versões e criou uma primeira versão unificada; 3 . avaliação da síntese por experts: a versão sintetizada foi avaliada por quatro juízes experts em avaliação psicológica e habilidades sociais para verificar a estrutura, o layout, as instruções do instrumento, a abrangência e a adequação das expressões contidas nos itens. Nessa etapa, foi discutido o uso do termo "sexo oposto" para se referir a possíveis parceiros amorosos. Após a análise de diversos termos alternativos, decidiu-se pela utilização do termo "pessoa atraente" ou "pessoa que considero atraente" para tornar a escala mais clara, de forma a se poder utilizar a escala em pessoas de diferentes orientações sexuais; 4. avaliação dos instrumentos pelo público-alvo: o instrumento foi aplicado em um grupo de pessoas pertencentes à população ao qual ele se destina para investigar possíveis problemas de compreensão das questões, no caso adultos; 5. tradução reversa (backtranslation): o instrumento foi novamente traduzido para o espanhol por dois tradutores que possuem o espanhol como língua materna e eram fluentes em português; 6 . síntese da tradução reversa: um terceiro tradutor realizou a síntese das duas versões traduzidas para o espanhol; 7. Avaliação do instrumento pelo autor original da escala: a versão traduzida e a tradução reversa foram enviadas para o autor original da escala para a avaliação e possíveis sugestões. Na Tabela 2, pode-se observar a comparação entre a versão original da escala e a nova tradução.

Tabela 2

Comparação entre a Versão Original da EMES-M e da Nova Tradução

\begin{tabular}{|c|c|}
\hline Versão original em espanhol & Versão Final em Português \\
\hline $\begin{array}{l}\text { 1. Cuando personas que apenas conozco me alaban, } \\
\text { intento minimizar la situación, quitando } \\
\text { importancia al hecho por el que soy alabado. }\end{array}$ & $\begin{array}{l}\text { Quando pessoas que mal conheço me elogiam, tento } \\
\text { minimizar a situação, tirando a importância do fato } \\
\text { pelo qual sou elogiado. }\end{array}$ \\
\hline $\begin{array}{l}2 \text { Cuando un vendedor se ha tomado una molestia } \\
\text { considerable en enseñarme un producto que no me } \\
\text { acaba de satisfacer, soy incapaz de decirle que «no». }\end{array}$ & $\begin{array}{l}\text { Quando um vendedor se esforça para mostrar um produto } \\
\text { que não gostei muito, sou incapaz de dizer que "não". }\end{array}$ \\
\hline $\begin{array}{l}3 \text { Cuando la gente me presiona para que haga cosas por } \\
\text { ellos, me resulta difícil decir que «no». }\end{array}$ & $\begin{array}{l}\text { Quando as pessoas me pressionam para fazer coisas } \\
\text { por elas, tenho dificuldade em dizer "não". }\end{array}$ \\
\hline 4 Evito hacer preguntas a personas que no conozco. & Evito fazer perguntas a pessoas que não conheço. \\
\hline 5 Soy incapaz de negarme cuando mi pareja me pide algo. & $\begin{array}{l}\text { Sou incapaz de dizer não quando minha (meu) } \\
\text { parceira(o) me pede algo. }\end{array}$ \\
\hline $\begin{array}{l}6 \text { Si un/a amigo/a me interrumpen medio de una } \\
\text { importante conversación, le pido que espere hasta que } \\
\text { haya acabado. }\end{array}$ & $\begin{array}{l}\text { Se um amigo me interrompe no meio de uma conversa } \\
\text { importante, peço-lhe para que espere até que eu tenha } \\
\text { terminado. }\end{array}$ \\
\hline $\begin{array}{l}7 \text { Cuando mi superior o jefe me irrita, soy capaz de } \\
\text { decírselo. }\end{array}$ & $\begin{array}{l}\text { Quando meu superior ou chefe me irrita, sou capaz de } \\
\text { dizer isso a ele. }\end{array}$ \\
\hline
\end{tabular}


Tabela 2 (continuação)

Comparação entre a Versão Original da EMES-M e da Nova Tradução

\begin{tabular}{|c|c|c|}
\hline & Versão original em espanhol & Versão Final em Português \\
\hline 8 & $\begin{array}{l}\text { Si un amigo/a a quien he prestado } 6 \text { euros parece } \\
\text { haberlo olvidado, se lo recuerdo. }\end{array}$ & $\begin{array}{l}\text { Se um amigo a quem emprestei dinheiro parece ter se } \\
\text { esquecido, eu lembro isso a ele. }\end{array}$ \\
\hline 9 & $\begin{array}{l}\text { Me resulta fácil hacer que mi pareja se sienta bien, } \\
\text { alabándola. }\end{array}$ & $\begin{array}{l}\text { ra mim é fácil fazer com que minha (meu) parceira(o) } \\
\text { sinta bem através de elogios. }\end{array}$ \\
\hline 10 & $\begin{array}{l}\text { Me aparto de mi camino para evitar problemas con } \\
\text { otras personas. }\end{array}$ & $\begin{array}{l}\text { Eu desvio do meu caminho para evitar problemas com } \\
\text { as outras pessoas. }\end{array}$ \\
\hline 11 & $\begin{array}{l}\text { roblema para mí mostrar a la gente mi agrado } \\
\text { los. }\end{array}$ & $\begin{array}{l}\text { m problema mostrar para as pessoas o } \\
\text { sto delas. }\end{array}$ \\
\hline 12 & $\begin{array}{l}\text { Si dos personas en un cine o en una conferencia están } \\
\text { hablando demasiado alto, les digo que se callen. }\end{array}$ & $\begin{array}{l}\text { inema ou em uma palestra e há duas } \\
\text { do muito alto, peço-lhes silêncio. }\end{array}$ \\
\hline 13 & $\begin{array}{l}\text { Cuando un atractivo miembro del sexo opuesto } r \\
\text { algo, soy incapaz de decirle que «no». }\end{array}$ & $\begin{array}{l}\text { pessoa que considero atraent } \\
\text {, sou incapaz de dizer "não". }\end{array}$ \\
\hline 14 & Cuando me siento enojado con alguien lo oculto. & Quando eu fico zangado com alguém, não o demonstro. \\
\hline 15 & o mis opiniones. & as opiniões para $n$ \\
\hline 16 & $\begin{array}{l}\text { cuidadoso/c } \\
\text { emás. }\end{array}$ & $\begin{array}{l}\text { nente cuidadoso } \\
\text { dos outros. }\end{array}$ \\
\hline 17 & $\begin{array}{l}\text { Cuando me atrae una persona a la que no he sido } \\
\text { presentado/a, intento de manera activa conocerla. }\end{array}$ & $\begin{array}{l}\text { traído por alguém que não c } \\
\text { tentar conhecê-la(o). }\end{array}$ \\
\hline 18 & Me resulta difícil hablaren público. & difícil falar em público. \\
\hline 19 & Soy incapaz de expresar desacuerdo & $\begin{array}{l}\text { le demonstrar que } \\
\text { parceira(o) }\end{array}$ \\
\hline 20 & $\begin{array}{l}\text { Evito hacer pregur } \\
\text { o timidez. }\end{array}$ & erguntas em aula ou no trabalho por medo \\
\hline & $\begin{array}{l}\text { Me resulta fácil hacer cumplidos a una persona que } \\
\text { apenas conozco. }\end{array}$ & $\begin{array}{l}\text { ácil fazer elogios a uma pess } \\
\text { co. }\end{array}$ \\
\hline 22. & $\begin{array}{l}\text { Cuando alguno de mis superiores me llama para } \\
\text { que haga cosas que no tengo obligación de hacer, soy } \\
\text { incapaz de decir que «no». }\end{array}$ & $\begin{array}{l}\text { Quando algum dos meus superiores me pede para fazer } \\
\text { coisas que não tenho a obrigação de fazer, sou incapaz } \\
\text { de dizer "não". }\end{array}$ \\
\hline 23. & Me resulta dificil hacer nuevos amigos/as. & Para mim é difícil fazer novos amigos. \\
\hline & $\begin{array}{l}\text { Si un/a amigo/a traiciona mi confianza, expreso } \\
\text { claramente mi disgusto a esa persona. }\end{array}$ & $\begin{array}{l}\text { Se um amigo quebra minha confiança, digo claramente } \\
\text { que estou decepcionado. }\end{array}$ \\
\hline 25. & Expreso sentimientos de cariño hacia mis padres. & Expresso sentimentos de carinho aos meus pais. \\
\hline 26. & Me resulta difícil hacer le un cumplido a un superior. & Para mim é difícil fazer um elogio a superiores. \\
\hline & $\begin{array}{l}\text { Si estuviera en un pequeño seminario o reunión y El } \\
\text { profesor o la persona que lo dirige hiciera }\end{array}$ & $\begin{array}{l}\text { Se eu estivesse em uma aula ou reunião e o professor } \\
\text { ou a pessoa que o dirige fizesse uma afirmação com a } \\
\text { qual não concordo, eu daria o meu ponto de vista. }\end{array}$ \\
\hline
\end{tabular}
mi propio punto de vista.

28. Si ya no quiero seguir saliendo con alguien del sexo opuesto, se lo hago saber claramente.

29. Soy capaz de expresar sentimientos negativos hacia extraños si me siento ofendido/a.

Se eu não quero continuar saindo com alguém, falo isso claramente para esta pessoa.

Sou capaz de expressar sentimentos negativos caso me sinta ofendido por estranhos.

30. Si en un restaurante me sirven comida que no está a mi Se, em um restaurante, me servem comida que não está gusto, me quejo de ello al camarero. ao meu gosto, reclamo disso com o garçom.

31. Me cuesta hablar con una persona atractiva del sexo opuesto a quien conozco sólo ligeramente.

Para mim é difícil falar com alguém que considero atraente e que conheço pouco.

32. Cuando He conocido a una persona que me agrada, Le pido El teléfono para un posible encuentro posterior.

Quando conheço uma pessoa que me agrada, eu peço o seu telefone para nos encontrarmos outra vez.

33. Si estoy enfadado con mis padres, se lo hago saber claramente.

Se estou zangado com os meus pais, eu falo isso claramente a eles.

34. Expreso mi punto de vista aun que sea impopular. Expresso meu ponto de vista mesmo que os outros não concordem.

35. Si alguien ha hablado mal de mí o me ha atribuido hechos falsos, le busco enseguida para poner los puntos sobre las íes.

Se alguém falou mal de mim, ou inventou coisas que não fiz, lhe procuro para "colocar os pingos nos is".

36. Me resulta difícil iniciar una conversación con un extraño. Começar uma conversa com um estranho é difícil para mim. 
Tabela 2 (continuação)

Comparação entre a Versão Original da EMES-M e da Nova Tradução

Versão original em espanhol Versão Final em Português

37. Soy incapaz de defender mis derechos ante mis superiores. Sou incapaz de defender meus direitos diante dos meus superiores.

38. Si una figura con autoridad me critica sin justificación, Se um superior me critica sem razão, é muito difícil me resulta difícil discutir su crítica abiertamente. para mim discutir sua crítica de forma aberta.

39. Si un miembro del sexo opuesto me critica injustamente, Se uma pessoa que considero atraente me critica le pido claramente explicaciones.

40. Dudo en solicitar citas por timidez. injustamente, eu lhe peço claramente explicações.

41. Me resulta fácil dirigirme y empezar una conversación con un superior. Fico em dúvida em relação a chamar alguém para sair, devido a minha timidez

Para mim é fácil me aproximar e começar uma conversa com um superior.

42. Con buenas palabras hago lo que los demás quieren que Na verdade, faço o que os outros querem que eu faça e haga y no lo que realmente querría Hacer. não o que eu realmente gostaria de fazer.

43. Cuando conozco gente nueva, tengo poco que decir. Quando conheço pessoas novas, não consigo falar muito.

44. Hago la vista gorda cuando alguien se cuela delante de mí en una fila

45. Soy incapaz de decir a alguien del sexo opuesto que me gusta.

Eu faço de conta que não vi quando alguém fura a fila na minha frente

Sou incapaz de dizer a alguém que considero atraente que eu gosto dela(e).

46. Me resulta difícil criticar a los demás incluso cuando está justificado.

Para mim é difícil criticar os outros, mesmo quando tenho motivos.

47. No sé qué decir a personas atractivas del sexo opuesto.

48. Si me doy cuenta de que me estoy enamorando de alguien con quien salgo, expreso estos sentimientos a esa persona.

Não sei o que dizer a pessoas que considero atraentes.

Se me dou conta de que estou me apaixonando por

alguém com quem estou saindo, expresso meus sentimentos a essa pessoa.

49. Si un familiar me critica injustamente, expreso mi enojo Se um familiar me critica injustamente, expresso espontánea y fácilmente. facilmente a minha raiva.

50. Me resulta fácil aceptar cumplidos provenientes de otras Para mim é fácil aceitar elogios de outras pessoas. personas.

51. Me río de las bromas que realmente me ofenden en vez de protestar o hablar claramente.

Eu dou risadas das piadas que na verdade me ofendem em vez de protestar ou falar que me ofendi.

52. Cuando me alaban, no sé qué responder. Quando me elogiam, não sei o que dizer.

53. Soy incapaz de hablaren público. Sou incapaz de falar em público.

54. Soy incapaz de mostrar afecto hacia un miembro del sexo opuesto.

Sou incapaz de demonstrar afeto a pessoas que considero atraente.

55. En las relaciones con mi pareja, es ella/él quien lleva el peso de las conversaciones.

Em meu relacionamento é a minha (meu) parceira(o) quem sempre tem razão.

56. Evito pedir algo a una persona cuando ésta se trata de Evito pedir algo a uma pessoa quando se trata de um un superior.

57. Si un pariente cercano y respetado me estuviera importunando, Le expresaría claramente mi malestar.

58. Cuando un dependiente en una tienda atiende a alguien que está detrás de mí, llamo su atención al respecto.

59. Me resulta difícil hacer cumplidos o alabar a un miembro del sexo opuesto. superior.

Se um parente próximo e respeitado estivesse me incomodando, eu expressaria claramente o meu aborrecimento.

Se em uma loja o funcionário atende primeiro alguém que chegou depois de mim, chamo sua atenção.

Para mim é difícil fazer elogios a uma pessoa que considero atraente.

60. Cuando estoy en un grupo, tengo problemas para encontrar cosas sobre las que hablar.

Quando estou em um grupo, tenho problemas para encontrar coisas sobre as quais falar.

61. Me resulta difícil mostrar afecto hacia otra persona en público.

62. Si un vecino del sexo opuesto, a quien he estado queriendo conocer, me para al salir de casa y me pregunta la hora, tomaría la iniciativa para empezar una conversación con esa persona

Para mim, é difícil mostrar afeto a outra pessoa em público.

Se um(a) vizinho(a) que considero atraente e que eu gostaria de conhecer me abordasse ao sair de casa e perguntasse a hora, tomaria a iniciativa para começar uma conversa.

63. Soy una persona tímida. Sou uma pessoa tímida.

64. Me resulta fácil mostrar mi enfado cuando alguien hace algo que me molesta.

Para mim é fácil demonstrar minha irritação quando alguém faz algo que me incomoda. 


\section{Estudo de Avaliação das Propriedades Psicométricas}

\section{Amostra}

Participaram deste estudo um total de 925 pessoas entre 18 e 35 anos. A idade média da amostra foi de 22,79 anos $(D P=3,59)$, sendo predominantemente do sexo feminino $(65,8 \%)$, e cursando o ensino superior $(55,6 \%)$. Os dados sociodemográficos da amostra podem ser observados na Tabela 3.

Tabela 3

Dados Sociodemográficos da Amostra do Estudo de Validação da EMES-M $(n=925)$

\begin{tabular}{lcc}
\hline \multicolumn{1}{c}{ Características } & $N$ & $\%$ \\
\hline Sexo & & \\
Masculino & 316 & 34,2 \\
Feminino & 609 & 65,8 \\
Estado Civil & & \\
Solteiro & 797 & 86,2 \\
Casado & 45 & 4,9 \\
Mora Junto & 53 & 5,7 \\
Separado/divorciado & 9 & 1 \\
Outro & 21 & 2,3 \\
& & \\
Escolaridade & & \\
Médio incompleto & 6 & 0,6 \\
Médio completo & 37 & 4 \\
Técnico incompleto & 3 & 0,3 \\
Técnico completo & 7 & 0,8 \\
Superior incompleto & 514 & 55,6 \\
Superior completo & 105 & 11,4 \\
Pós Graduação & 87 & 9,4 \\
Não informado & 166 & 17,9 \\
Região & & \\
Norte & & \\
Nordeste & 63 & 6,81 \\
Centro-oeste & 155 & 16,76 \\
Sul & 111 & 12 \\
Sudeste & 328 & 35,46 \\
\hline & 268 & 28,97 \\
\hline & &
\end{tabular}

\section{Instrumentos}

Ficha sociodemográfica. Avaliação do perfil sociodemografico da amostra, como idade, sexo, escolaridade e região do país que reside.

Dimensional Anxiety Scale - Social Anxiety Disorder (SAD-D). Medida dimensional breve de autorrelato apresentada no DSM-5 como sugestão de medida para diagnosticar sintomas de ansiedade social. A escala solicita ao respondente que avalie, em relação aos últimos sete dias, a partir de uma escala de 5 pontos $(0-$ nunca a 5 - o tempo todo), o quanto as afirmativas representam seus sintomas físicos e cognitivos de ansiedade, bem como seus comportamentos frente a situações aversivas presentes no transtorno de ansiedade social. Foi adaptada por DeSousa et al. (2016) apresentando propriedades psicométricas adequadas.

Escala Mini-Spin (D'el Rey, Lacava, \& Cardoso, 2007; Osório, Crippa, \& Loureiro, 2007). É um instrumento de autorrelato composto por três itens, que avaliam medo de constrangimento e evitação. Para cada um dos itens do inventário, solicita-se ao indivíduo que marque, em uma escala de cinco pontos, que variam de nada (0) a extremamente (4), o quanto as situações o incomodaram na última semana. Escores de seis pontos ou mais indicam a necessidade de se investigar a presença de fobia social generalizada.

Escala Rathus de Assertividade (escala validada para a população brasileira por Pasquali e Gouveia,1990). É composta por 30 itens que descrevem comportamentos em relação a situações do cotidiano. Tem por objetivo avaliar as habilidades assertivas necessárias para lidar com as situações do cotidiano. Para responder às questões, aos respondentes é fornecida uma escala que varia do +3 (extremamente parecido comigo) a -3 (extremamente diferente de mim). Como proposto pelos autores em sua versão brasileira, as análises deste estudo utilizaram apenas o fator principal composto por 20 itens, pois apresenta os melhores indicadores de validade.

\section{Análise de Dados}

Para a análise das propriedades psicométricas, foram realizadas análises fatoriais confirmatórias utilizando-se o software Mplus e o método de Weighted Least Squares Means and Variance Adjusted (WLSMV), visto que este é mais adequado à natureza categórica dos itens dessa escala. Como índices de ajuste, foram calculados o CFI, TLI e RMSEA com $90 \%$ de intervalo de confiança. Valores de CFI e TLI acima de 0,9 foram considerados como um ajuste aceitável e acima de 0,95 como um bom ajuste. Para os valores de RMSEA, foram considerados valores abaixo de 0,08 , como um ajuste aceitável e valores abaixo de 0,05, como bom ajustamento (Hu \& Bentler, 1999). Os modelos com melhores índices de ajuste foram utilizados para as demais análises.

Para análises da consistência interna das escalas, foi calculado o alfa de Crombach, sendo considerados valores entre 0,7 e 0,9 como ideais. Para a realização de análises convergentes, foram desenvolvidas correlações de Pearson com as escalas Dimensional Social Anxiety Scale (SAD-D) e versão reduzida do Social Phobia Inventory (MiniSpin), as quais avaliam ansiedade social. A literatura aponta uma grande correlação entre níveis baixos de habilidades sociais e a presença de ansiedade social (Pereira, Wagner, \& Oliveira, 2014). Realizou-se também análises convergentes com a Escala de Assertividade de Rathus que avalia assertividade, um construto considerado chave para as habilidades sociais. 


\section{Procedimentos}

\section{Coleta de Dados}

Coleta de dados on-line a partir da plataforma Survey Monkey. A divulgação ocorreu por meio de grupos de e-mail, das redes sociais e do método bola de neve (participantes indicavam novos participantes). Todos os participantes responderam ao Termo de Consentimento Livre Esclarecido eletrônico. Como critérios de inclusão estavam: indivíduos de ambos os sexos, possuir entre 18 e 35 anos e ter respondido ao protocolo de pesquisa completo. Foram excluídos participantes que responderam às questões-controle de forma errada. Estas solicitavam aos participantes que marcassem uma opção específica, de forma a evitar a marcação aleatória de questões (ex.: Nesta questão, marque a opção 4).

\section{Resultados}

Para a investigação da estrutura fatorial da EMES-M, primeiramente foram invertidas as questões que possuíam valências negativas no questionário. Após, foi realizada uma análise fatorial confirmatória (CFA) utilizando o modelo original de 12 fatores (Caballo, 1993). Esse modelo apresentou problemas de variância que impediam que os dados pudessem ser interpretados pelo software de análises estatísticas. Buscou-se identificar quais fatores poderiam estar causando esse problema. Como relatado por Costello e Osborne (2005), fatores que possuem menos de três itens devem ser desconsiderados por não serem estáveis. Assim, optou-se por eliminar os dois fatores do modelo original da escala que possuíam essa característica (fatores 11 e 12).

Com essa modificação, os problemas de variância foram resolvidos, porém o modelo apresentou índices de ajustes abaixo do aceitável (Tabela 4). Além disso, diversos itens não carregaram em seus fatores. A partir desse resultado, decidiu-se realizar um reagrupamento teórico dos itens em novas categorias, de forma a identificar a quais habilidades cada itens se referia. Essa análise foi realizada por dois juízes independentes que possuíam domínio da teoria das habilidades sociais. Os juízes avaliaram todas as questões do instrumento e as agruparam em categorias de habilidades que estavam avaliando. A partir dessa análise, cinco itens foram excluídos pelos juízes por não serem claros a que habilidade social se referiam (itens 10, 16, 28, 56 e 63). Por fim, foram definidas oito categorias teoricamente embasadas, nas quais os demais itens foram alocados.

Essas nova divisão teórica foi testada a partir de uma nova CFA. Os itens 05, 27 e 41 não apresentaram cargas fatoriais adequadas (abaixo de 0,3) e foram excluídos da escala. A partir disso, a nova estrutura fatorial foi composta por oito fatores e 56 itens. Os índices de ajuste podem ser observados na Tabela 4.

Tabela 4

Índices de Ajuste dos Modelos Testados da EMES-M

\begin{tabular}{lcccc}
\hline \multicolumn{1}{c}{ Modelo } & $\chi^{2}$ (graus de liberdade) & CFI & TLI & RMSEA (90\% CI) \\
\hline Modelo Original sem fatores 11 e 12 & $4661,957(1080)$ & 0,898 & 0,889 & $0,059(0,058-0,061)$ \\
Modelo de 8 fatores teóricos & $4778,262(1456)$ & 0,910 & 0,904 & $0,049(0,048-0,051)$ \\
\hline
\end{tabular}

Dessa forma, a nova versão da EMES-M para a população brasileira é composta pelos seguintes fatores: Habilidade para iniciar e manter conversações (ex.: 04 - Evito fazer perguntas a pessoas que não conheço); Habilidades para dizer não (ex.: 02 - Quando um vendedor se esforça para mostrar um produto que não gostei muito, sou incapaz de dizer que "não"); Habilidades em receber elogios (ex.: 50 - Para mim é fácil aceitar elogios de outras pessoas); Habilidades para falar em público (ex.: 20 - Evito fazer perguntas em aula ou no trabalho por medo ou timidez.); Habilidades para expressar afeto positivo (ex.: 21 - Para mim, é fácil fazer elogios a uma pessoa que conheço pouco); Habilidades para expressar afeto negativo (ex.: 24 - Se um amigo quebra minha confiança, digo claramente que estou decepcionado); Habilidades para expressar desacordo/opiniões contrárias (ex.: 34); Habilidades para defender direitos (ex.: 12 - Se estou no cinema ou em uma palestra e há duas pessoas falando muito alto, peço-lhes silêncio). As cargas fatoriais de cada item em seus respectivos fatores, bem como a consistência interna dos fatores testada a partir do alfa de Cronbach pode ser observada na Tabela 5.

Tabela 5

Descrição da Estrutura Fatorial e dos Alfas de Cronbach da EMES-M a partir dos Comportamentos (Escala Total $\alpha=0,945)$

\begin{tabular}{cccc}
\hline Fator (alfa) e Itens & Carga Fatorial & Fator (alfa) e Itens & Carga Fatorial \\
\hline CONVERSAS $(\alpha=0,883)$ & & DIZER NÃO $(\alpha=0,740)$ & 0,579 \\
\hline EMES-M 04* & 0,659 & EMES-M 02* & 0,698 \\
EMES-M 17 & 0,546 & EMES-M 03* & 0,547
\end{tabular}


Tabela 5 (continuação) Descrição da Estrutura Fatorial e dos Alfas de Cronbach da EMES-M a partir dos Comportamentos (Escala Total $\alpha=0,945)$

\begin{tabular}{|c|c|c|c|}
\hline Fator (alfa) e Itens & Carga Fatorial & Fator (alfa) e Itens & Carga Fatorial \\
\hline EMES-M $31^{*}$ & 0,749 & EMES-M 19* & 0,612 \\
\hline EMES-M 32 & 0,501 & EMES-M 22* & 0,549 \\
\hline EMES-M 36* & 0,736 & EMES-M 42* & 0,697 \\
\hline EMES-M 40* & 0,725 & & \\
\hline EMES-M 43* & 0,791 & & \\
\hline EMES-M 47* & 0,808 & & \\
\hline EMES-M 60* & 0,710 & & \\
\hline EMES-M 62 & 0,631 & & \\
\hline SER ELOGIADO $(\alpha=0,718)$ & \multicolumn{3}{|c|}{ FALAR PÚBLICO $(\alpha=0,829)$} \\
\hline EMES-M 01* & 0,636 & EMES-M 18* & 0,835 \\
\hline EMES-M 50 & 0,717 & EMES-M 20* & 0,804 \\
\hline EMES-M 52* & 0,780 & EMES-M 53* & 0,907 \\
\hline AFETO $+(\alpha=0,831)$ & \multicolumn{3}{|c|}{ AFETO - $(\alpha=0,724)$} \\
\hline EMES-M 09 & 0,472 & EMES-M 07 & 0,311 \\
\hline EMES-M $11^{*}$ & 0,676 & EMES-M 14* & 0,506 \\
\hline EMES-M 21 & 0,507 & EMES-M 24 & 0,604 \\
\hline EMES-M 25 & 0,399 & EMES-M 29 & 0,515 \\
\hline EMES-M 26* & 0,483 & EMES-M 33 & 0,531 \\
\hline EMES-M 45* & 0,805 & EMES-M 49 & 0,552 \\
\hline EMES-M 48 & 0,548 & EMES-M 51* & 0,456 \\
\hline EMES-M 54* & 0,780 & EMES-M 57 & 0,643 \\
\hline EMES-M 59* & 0,790 & EMES-M 64 & 0,662 \\
\hline EMES-M 61* & 0,658 & & \\
\hline DESACORDO $(\alpha=0,738)$ & \multicolumn{3}{|c|}{ DIREITOS $(\alpha=0,712)$} \\
\hline EMES-M 15* & 0,581 & EMES-M 06 & 0,447 \\
\hline EMES-M 34 & 0,719 & EMES-M 08 & 0,472 \\
\hline EMES-M 35 & 0,549 & EMES-M 12 & 0,605 \\
\hline EMES-M 38* & 0,574 & EMES-M 30 & 0,539 \\
\hline EMES-M 39 & 0,546 & EMES-M 37* & 0,604 \\
\hline EMES-M 46* & 0,675 & EMES-M 44* & 0,613 \\
\hline EMES-M 55* & 0,346 & EMES-M 58 & 0,569 \\
\hline
\end{tabular}

Nota. *Itens que devem ter sua pontuação invertida para interpretação dos resultados

Para a realização da validação convergente da escala, foram selecionadas as subamostras que responderam, além da EMES-M, as escalas SAD-D, Mini-Spin e a Escala de Assertividade de Rathus. Como pode ser observado na Tabela 6, as três escalas obtiveram correlações negativas estatisticamente significativas com o escore total da EMES-M.

Também foram realizadas comparações entre grupos a partir da idade e de sexo para avaliar a validade de critério a partir de teste $t$, visto que a literatura aponta que as habilidades sociais variam com a idade e de que mulheres são socialmente mais hábeis que homens (Caballo, 2003; Del Prette \& Del Prette, 2009; Furtado, Falcone, \& Clark, 2003). Para realizar a comparação de idade, a amostra foi dividida entre os participantes que possuíam mais de 25 anos e os que possuíam menos. Essas comparações podem ser observadas na Tabela 7. Houve diferença significativa dos escores totais da EMES-M tanto nas comparações dos grupos divididos por idade quanto por sexo. Em relação ao sexo, houve diferenças nos fatores habilidade para iniciar e manter conversações, Habilidades em falar em público e Habilidades para expressar afeto positivo e negativo, nas quais as mulheres apresentaram médias superiores. Em relação a idade, os participantes mais velhos apresentaram escores superiores nos fatores Habilidade para iniciar e manter conversações, Habilidades para falar em público, Habilidades para expressar afeto positivo e Habilidades para defender direitos. 
Tabela 6

Correlações Entre a EMES-M e seus Fatores com as Escalas SAD-D, Mini-Spin e Escala de Assertividade Rathus

\begin{tabular}{llcc}
\hline & SAD-D & Mini-Spin & Rathus $^{1}$ \\
\hline EMES-M Conversas &,$- 487^{* *}$ &,$- 669^{* *}$ &,,$- 706^{* *}$ \\
EMES- M Dizer não &,$- 413^{* *}$ &,$- 468^{* *}$ &,$- 705^{* *}$ \\
EMES- M Ser Elogiado &,$- 365^{* *}$ &,$- 462^{* *}$ &,$- 565^{* *}$ \\
EMES- M Falar em Público &,$- 465^{* *}$ &,$- 621^{* *}$ &,$- 608^{* *}$ \\
EMES- M Afeto + &,$- 426^{* *}$ &,$- 539^{* *}$ &,$- 618^{* *}$ \\
EMES- M Afeto - &,$- 231^{* *}$ &,$- 343^{* *}$ &,$- 586^{* *}$ \\
EMES- M Desacordo &,$- 371^{* *}$ &,$- 527^{* *}$ &,$- 688^{* *}$ \\
EMES- M Direitos &,$- 354^{* *}$ &,$- 469^{* *}$ &,$- 709^{* *}$ \\
EMES- M Total &,$- 519^{* *}$ & $-689^{* *}$ &,$- 855^{* *}$ \\
\hline
\end{tabular}

Nota. ${ }^{* *} p<0,001 ;{ }^{1}$ A Escala de Assertividade de Rathus possui um escore invertido, logo, quanto maior a pontuação, menos a pessoa é assertiva

Tabela 7

Comparações Entre Grupos Divididos por Idade e Sexo nos Escores da EMES-M

\begin{tabular}{|c|c|c|c|c|c|c|}
\hline & \multicolumn{3}{|c|}{ Idade } & \multicolumn{3}{|c|}{ Sexo } \\
\hline & $<25$ anos & $=25$ anos & $p$ & Masculino & Feminino & $p$ \\
\hline EMES-M Total & $164,08(34,82)$ & $171,15(31,97)$ & $0,005^{*}$ & $162,67(34,50)$ & $167,76(33,92)$ & $0,032^{*}$ \\
\hline Conversas & $28,49(9,54)$ & $30,12(9,25)$ & $0,020^{*}$ & $27,72(9,63)$ & $29,58(9,35)$ & $0,005^{*}$ \\
\hline Dizer Não & $19,87(4,59)$ & $20,25(4,48)$ & 0,261 & $19,69(4,46)$ & $20,12(4,60)$ & 0,172 \\
\hline Ser Elogiado & $8,19(2,90)$ & $8,39(2,87)$ & 0,353 & $8,28(2,82)$ & $8,23(2,93)$ & 0,803 \\
\hline Falar em Publico & $9,03(3,62)$ & $9,79(3,55)$ & $0,005^{*}$ & $9,84(3,55)$ & $8,92(3,62)$ & $<0,001^{* *}$ \\
\hline Afeto + & $29,47(8,06)$ & $31,17(7,30)$ & $0,003^{*}$ & $29,13(8,02)$ & $30,36(7,79)$ & $0,025^{*}$ \\
\hline Afeto - & $27,86(6,19)$ & $28,69(5,85)$ & 0,067 & $26,91(5,93)$ & $28,70(6,11)$ & $<0,001^{* *}$ \\
\hline Desacordo & $22,00(5,18)$ & $22,46(4,69)$ & 0,213 & $21,90(5,15)$ & $22,24(5,00)$ & 0,342 \\
\hline Direitos & $19,16(5,15)$ & $20,30(5,27)$ & $0,003^{*}$ & $19,20(4,91)$ & $19,62(5,34)$ & 0,233 \\
\hline
\end{tabular}

Nota. ${ }^{*} p<0,05 ;{ }^{* *} p<0,001$

\section{Discussão}

Como demonstrado nos resultados, a estrutura fatorial original da EMES-M publicada por Caballo (2003) não se adequou à população brasileira. Algumas razões podem ser apontadas para esse problema, como a existência de fatores com apenas um ou dois itens, o que prejudica as análises estatísticas da escala, e é desencorajado pela literatura (Costello \& Osborne, 2005). Outro aspecto observado foi o carregamento de alguns itens em mais de um fator e itens que carregaram em fatores diferentes do previsto na versão original. Justamente para transpor esses problemas, avaliou-se uma nova estrutura fatorial para à escala, adequada à população brasileira, alternativa à versão disponível (mais especificamente: Caballo, 2003).

O reagrupamento dos itens a partir das habilidades avaliadas em novos fatores realizado por dois juízes foi testada a partir de uma CFA e apresentou índices de ajustamento adequados. Decidiu-se por realizar uma estrutura baseada teoricamente, uma vez que existe uma ampla teoria que sustenta o estudo das habilidades sociais, proposta inclusive pelo próprio criador da escala (Caballo, 2003).

Excluiu-se cinco dos itens originais da escala por estes não se adequarem às categorias encontradas, além de não se referirem a habilidades avaliadas por outros itens, impedindo sua inclusão nos fatores. Mesmo os itens trazendo informações que possam ser qualitativamente interessantes, eles foram desconsiderados no levantamento dos escores fatoriais e total da escala. Estes itens são: 10 (Eu desvio do meu caminho para evitar problemas com as outras pessoas), 16 (Sou extremamente cuidadoso para evitar ferir os sentimentos dos outros, 28 (Se eu não quero continuar saindo com alguém, falo isso claramente para essa pessoa), 56 (Evito pedir algo a uma pessoa quando se trata de um superior) e 63 (Sou uma pessoa tímida). Além destes, outros três itens não carregaram nos fatores os quais avaliavam as habilidades que estes se propunham a avaliar. Como isso, pode significar que os itens não estão sendo bem entendidos pelos respondentes ou que estão mal construídos, decidiu-se por 
excluí-los. Estes itens são: 05 (Sou incapaz de dizer não quando minha (meu) parceira(o) me pede algo), 27 (Se eu estivesse em uma aula ou reunião e o professor ou a pessoa que o dirige fizesse uma afirmação com a qual não concordo, eu daria o meu ponto de vista.), 41 (Para mim, é fácil me aproximar e começar uma conversa com um superior),

Quanto à validade convergente, as correlações entre a escala de Assertividade de Rathus e o escore da EMES-M foi elevada, demonstrando que as duas escalas avaliam construtos semelhantes, o que corrobora a literatura, pois a assertividade é considerada uma importante habilidade social e está relacionada a uma maior expressão das demais habilidades (Del Prette \& Del Prette, 2002). Lembrando que, no levantamento do escore da Escala de assertividade de Rathus, quanto maior a pontuação, menor a ocorrência de comportamentos assertivos relatados, o que explica a correlação negativa.

Ao avaliar as correlações entre a EMES-M e as escalas Mini-Spin e SAD-D, o resultado demonstra o que é apontado pela literatura, que a falta de habilidades sociais tende a aumentar a probabilidade de ansiedade social, pela inabilidade do sujeito em lidar com as demandas exigidas pelas interações sociais (Pereira et al., 2014), o que justifica a correlação negativa entre as escalas. Em relação aos fatores da EMES-M, percebe-se que aqueles que apresentaram maior correlação com as escalas Mini-Spin e Sad-D foram os fatores Iniciar conversação e Falar em público. Esse resultado demonstra que essas são, possivelmente, as habilidades sociais que apresentam maiores déficits em pessoas com altos níveis de ansiedade social.

Ao se observar as comparações por grupos de idade e sexo, percebe-se que existe uma diferença significativa entre jovens com menos de 24 anos em comparação àqueles acima de 24 anos. Essa análise foi realizada para observar se a escala é sensível às diferenças de idade, visto que, o repertório de habilidades sociais se desenvolve durante toda a vida. Jovens mais velhos tendem a ser mais socialmente hábeis, visto que possuem mais experiências de vida, por meio das quais puderam incrementar suas habilidades. Porém chama a atenção que, nos fatores Habilidade para dizer não, Habilidades em receber elogios e nas Habilidades em expressar desacordo e afeto negativo não houve diferenças significativas. Esse dado pode significar que essas habilidades não são desenvolvidas ao longo do tempo, ou ainda que elas podem ser adquiridas em um momento prévio no ciclo vital, visto que a amostra deste estudo é de adultos jovens, dessa forma, não havendo diferença entre jovens mais novos e mais velhos. Em relação à comparação entre homens e mulheres, a literatura aponta que mulheres tendem a ser mais socialmente habilidosas que homens (Caballo, 2003; Furtado et al., 2003; Del Prette \& Del Prette, 2009), os resultados deste estudo também apontaram isso ao identificar que houve diferenças significativas entre as médias de homens e mulheres no escore total e nos fatores iniciar e manter conversações, falar em público e expressão de afeto negativo e positivo.

\section{Considerações Finais}

O objetivo deste trabalho foi desenvolver uma nova adaptação brasileira da Escala Multidimensional de Expressão Social Parte Motora (Habilidades Sociais). Para tanto, foram realizada nova tradução e a atualização de termos que estão em desuso. Este estudo também buscou levantar evidências psicométricas de validade, encontrando nova estrutura fatorial com índices de ajuste aceitáveis e que se mostra adequada nas análises de validade convergente e de consistência interna.

Em relação às limitações deste estudo, é preciso levar em conta que a amostra utilizada foi apenas de jovens entre 18 e 35 anos, dessa forma, não existem dados que atestem a validade do instrumento em pessoas fora dessa faixa etária. Da mesma forma, é preciso salientar que a amostra utilizada neste estudo, mesmo sendo consideravelmente grande, apresenta homogeneidade em suas características sociodemográficas. Assim, novos estudos devem ser realizados com amostras mais diversificadas para avaliar se a estrutura apresentada será útil para populações diferentes da estudada. Sugere-se também que sejam realizados estudos com amostras clínicas, para observar se o instrumento é sensível o suficiente para diferenciar pessoas com e sem condições clínicas significativas. É importante salientar que, para utilização dessa escala em um contexto clínico, para avaliação de pacientes ou no uso de processos de psicodiagnóstico são necessários novos estudos para realização da normatização da escala e o desenvolvimento de manuais para o uso e correção padronizada.

Por fim, a nova estrutura fatorial composta por oito fatores da EMES-M se mostra adequada e abrange um número significativo de habilidades sociais. Dessa forma, conclui-se que a nova versão da EMES-M é indicada para uso em jovens brasileiros entre 18 a 35 anos em contexto de pesquisas.

\section{Referências}

American Psychiatric Association, APA. (2014). Manual Diagnóstico e Estatístico de Transtornos Mentais. DSM-5 (5ª ed.). Porto Alegre: Artmed. Angélico, A. P., Crippa, J. A. S., \& Loureiro, S. R. (2012). Utilização do inventário de habilidades sociais no diagnóstico do transtorno de ansiedade social. Psicologia: Reflexão e Crítica, 25(3), 467-476. doi:10.1590/S0102-79722012000300006 
Bandeira, M., Quaglia, M. A. C., Bachetti, L. D. S., Ferreira, T. L., \& Souza, G. G. D. (2005). Comportamento assertivo e sua relação com ansiedade, locus de controle e autoestima em estudantes universitários. Estudos de Psicologia (Campinas), 22(2), 111-121. doi:10.1590/ S0103-166X2005000200001

Borsa, J. C., Damásio, B. F., \& Bandeira D. R. (2012). Adaptação e validação de instrumentos psicológicos entre culturas: Algumas considerações. Paideia, 22(53), 423-432. doi: 10.1590/1982-43272253201314

Caballo, V. E. (1993). La multidimensionalidad conductual de las habilidades sociales: propriedaddes psicometricas de uma medida de autoinforme, la EMES-M. Psicologia Conductual, 1(2), 221-231. Recuperado de https://www.researchgate.net/publication/259527633

Caballo, V. E. (2003). Manual de avaliação e treinamento das habilidades sociais. São Paulo: Santos.

Caballo, V. E., \& Ortega, A. R. (1989). La escala multidimensional de expresión social: algunas propiedades psicometricas. Revista de Psicologia: General y Aplicada, 42(2), 215-221. Recuperado de https://www.researchgate.net/publication/28176273

Carneiro, R. S., \& Falcone, E. M. D. O. (2004). Um estudo das capacidades e deficiências em habilidades sociais na terceira idade. Psicologia em Estudo, 9(1), 119-126. doi:10.1590/S1413-73722004000100015

Costello, A. B., \& Osborne, J. W. (2005). Best practices in exploratory factor analysis: Four recommendations for getting the most from your analysis. Practical Assessment, Research \& Evaluation, 10(7), 1-9. Recuperado de https://pareonline.net/pdf/v10n7.pdf

Cronbach, L. J.(1951).Coefficient Alpha and the internal structure of tests. Psychometrika, 16(3), 297-334. doi: 10.1007/BF02310555

Del Prette, Z. A, \& Del Prette, A.(2002). Transtornos psicológicos e habilidades sociais. In Guillardi, H. J. (Ed.), Sobre comportamento e cognição: Contribuições da construção da teoria do comportamento (pp. 377-386). São Paulo: ESETec

Del Prette, Z.A.P., \& Del Prette, A. (2009). Psicologia das Habilidades Sociais: diversidade teórica e suas implicações. Petrópolis: Vozes.

D'el Rey, G. J. F., Lacava, J. P. L., \& Cardoso, R. (2007). Consistência interna da versão em português do Mini-Inventário de Fobia Social (Mini-SPIN). Revista de Psiquiatria Clínica, 34(6), 266-269. doi:10.1590/S0101-60832007000600002

DeSousa, D. A., Moreno, A. L., Osório, F. L., Crippa, J. A. S., LeBeau, R., Manfro, G. G., \& Koller, S. H. (2016). Psychometric properties of the dimensional anxiety scales for DSM- 5 in a Brazilian community sample. International Journal of Methods in Psychiatric Research, 26(3), 1-10. doi: 10.1002/mpr.1531

Furtado, E. S., Falcone, E. M. O., \& Clark, C. (2003). Avaliação do estresse e das habilidades sociais na experiência acadêmica de estudantes de medicina de uma universidade do Rio de Janeiro. Interação em Psicologia, 7(2), 43-51. doi:10.5380/psi.v7i2.3222

Hu, L., \& Bentler, P. M.(1999).Cut off criteria for fit indexes in covariance structure analysis: Conventional criteria versus new alternatives. Structural Equation Modeling: A Multidisciplinary Journal, 6(1), 1-55. doi: 10.1080/10705519909540118

Landim, A. K. P. et al. (2000). Ansiedade social em estudantes universitários: Preocupações mais emergentes. Revista Unicastelo, $3,185-192$.

Osório, F. de L., Crippa, J. A., \& Loureiro, S. R. (2007). A study of the discriminative validity of a screening tool (MINI-SPIN) for social anxiety disorder applied to Brazilian university students. European Psychiatry, 22(4), 239-243. doi:10.1016/j.eurpsy.2007.01.003

Pasquali, L., \& Gouveia, V. V. (1990). Escala de assertividade de Rathus - RAS: Adaptação brasileira. Psicologia: Teoria e Pesquisa, 6(3), $233-249$. Recuperado de http://www.vvgouveia.net/sp/images/Gouveia_1990_Escala_de_assertividade.pdf

Penn, D. L., Kohlmaier, J. R., \& Corrigan, P. W. (2000). Interpersonal factors contributing to the stigma of schizophrenia: Social skills, perceived attractiveness, and symptoms. Schizophrenia Research, 45(1), 37-45. doi:10.1016/S0920-9964(99)00213-3

Pereira, A. S.(2015) Avaliação das habilidades sociais e suas relações com fatores de risco e proteção em jovens adultos brasileiros (Dissertação de mestrado). Universidade Federal do Rio Grande do Sul, Porto Alegre, RS.

Pereira, A. S., Dutra-Thomé, L., \& Koller, S. H. (2016). Habilidades sociais e fatores de risco e proteção na adultez emergente. Psico, 47(4), 268-278. doi: 10.15448/1980-8623.2016.4.23398

Pereira, A. S., Wagner, M. F., \& Oliveira, M. S. (2014). Déficits em habilidades sociais e ansiedade social: Avaliação de estudantes de psicologia. Psicologia da Educação, 38, 224-244. Recuperado de http://pepsic.bvsalud.org/pdf/psie/n39/n39a10.pdf

Pereira, A. S., Rodriges, A. Wi., Koller, S. H., \& Almeida, R. M. M. (2016) Fatores de Risco e Proteção para Tentativa de suicídio na adultez emergente. Revista Ciência e Saúde Coletiva, 526, 1-1. Recuperado de http://www.cienciaesaudecoletiva.com.br/artigos/fatores-de-riscoe-protecao-para-tentativa-de-suicidio-na-adultez-emergente/15952?id=15952

Segrin, C. (2000). Social skills deficits associated with depression. Clinical Psychology Review, 20(3), 379-403. doi: 10.1016/S02727358(98)00104-4

Sbicigo, J. B., \& Lisbôa, C. S. de M. (2009). Habilidades sociais e satisfação conjugal: Um estudo correlacional. Revista Brasileira de Terapias Cognitivas, 5(2), 73-81. Recuperado de http://pepsic.bvsalud.org/pdf/rbtc/v5n2/v5n2a08.pdf

Sztamfater, S., \& Savóia, M. G. (2010). O impacto da inserção de familiares no tratamento do portador adulto de fobia social. Acta Médica Portuguesa, 23(1), 25-32.

Wagner, M. F., Pereira, A. S., \& Oliveira, M. S. (2014). Intervención sobre las dimensiones de la ansiedad social por medio de um programa de entrenamiento en habilidades sociales. Psicología Conductual, 22(3), 423-448. Recuperado de http://www.funveca.org/revista/pedidos/ product.php?id_product $=647$

recebido em abril de 2017 aprovado em fevereiro de 2018

\section{Sobre os autores}

Anderson Siqueira Pereira é psicólogo, Mestre e doutorando em Psicologia pela Universidade Federal do Rio Grande do Sul.

Luciana Dutra-Thomé é psicóloga e Doutora em Psicologia. Atualmente é professora do Instituto de Psicologia da Universidade Federal da Bahia.

Silvia Helena Koller é psicóloga e Doutora em Psicologia. Atualmente é professora pela Universidade Federal do Rio Grande do Sul. 